\title{
VERIFIKASI FORMAL PROTOKOL AUTENTIKASI LINTAS REALM BERBASIS KUNCI PUBLIK
}

\author{
Sepha Siswantyo ${ }^{1}$, Muhammad Ziyad Al-Malik ${ }^{2}$ \\ Program Studi Rekayasa Kriptografi, Politeknik Siber dan Sandi Negara, Bogor ${ }^{1,2}$ \\ e-mail: sepha.siswantyo@poltekssn.ac.id ${ }^{1}$,m.ziyad@ student.poltekssn.ac.id ${ }^{2}$
}

\begin{abstract}
Abstrak
Banyak perusahaan telah memanfaatkan integrasi berbagai sistem seperti sistem computer aided design dan sistem manufaktur untuk dijalankan antar host dan antar unit organisasi. Perkembangan teknologi Internet of Things dan blockchain juga berpotensi untuk diterapkan pada sistem terdistribusi. Aspek keamanan menjadi bagian penting dalam sistem terdistribusi maupun sistem yang membutuhkan akses data maupun layanan antar domain atau realm, oleh karena itu diperlukan mekanisme autentikasi lintas realm untuk menjamin keaslian dari setiap entitas yang akan berkomunikasi. Desain protokol autentikasi lintas realm perlu diverifikasi secara formal untuk menjamin keamanan protokol ketika diimplementasikan di dunia nyata. Penelitian ini melakukan analisis atau verifikasi formal terhadap protokol autentikasi lintas realm berbasis kunci publik yang didesain oleh Xiong dkk. menggunakan metode analisis protokol keamanan yang terdiri dari pemodelan protokol dan penyerang, penentuan kriteria keamanan, dan pembuktian atau pemeriksaan kriteria keamanan dengan alat verifikasi Scyther. Klaim keamanan yang dianalisis adalah kerahasiaan parameter dan autentikasi entitas. Hasil verifikasi menunjukkan dari 35 klaim keamanan (kerahasiaan dan autentikasi), terdapat 33 klaim sukses dan 2 klaim gagal.
\end{abstract}

Kata kunci : Autentikasi Lintas Realm; Verifikasi Formal; Scyther

\begin{abstract}
Many enterprises have implemented the integration of various systems such as computer-aided design systems and manufacturing systems to run between hosts and organizational units. The development of the Internet of Things and blockchain technology also potential to be applied to distributed systems. The security aspect is an essential part of distributed systems and systems that require data access and services between domains or realms. Therefore a cross-realm authentication mechanism is needed to ensure the authenticity of each entity that will communicate. The design of cross-realm authentication protocol needs to be formally verified to ensure the security of protocol when implemented in the real world. This research conducted formal analysis or verification of cross-realm authentication protocol based on public-key designed by Xiong et al. using security protocol analysis method which consists of protocol and adversary modelling, specifying security criteria, and proving or checking security criteria with Scyther verification tool. Security claims analyzed are secrecy of parameters and entity authentication. The verification results show that out of 35 security claims (secrecy and authentication), there are 33 successful claims and two failed claims.
\end{abstract}

Keywords : Cross; Realm Authentication; Formal Verification; Scyther 


\section{PENDAHULUAN}

Perkembangan teknologi jaringan dan perangkat teknologi informasi mendorong inovasi sistem maupun aplikasi untuk menunjang proses bisnis suatu perusahaan, khususnya yang berskala besar. Pada umumya, jaringan perusahaan berskala besar bersifat heterogen dan terdiri dari sekumpulan komputer, sistem operasi, dan perangkat yang bervariasi [1]. Demikian pula bagi perusahaan yang bergerak di bidang industri. Kebutuhan terhadap integrasi beragam aplikasi semakin meningkat disebabkan perkembangan lingkungan industri yang semakin terdistribusi dan heterogen (lintas organisasi maupun geografi) [1]. Berbagai macam aplikasi di bidang industri, seperti sistem computer-aided design (CAD), sistem manajemen dokumen teknis, sistem manufaktur, dan sistem manajemen data produksi dapat diintegrasikan dan dijalankan antar host. Tidak hanya aplikasi berskala besar, penggunaan perangkat Internet of Things (IoT) dan teknologi blockchain juga berpotensi untuk diterapkan pada sistem yang terdistribusi dan membutuhkan pertukaran informasi yang efektif dari segi biaya, contohnya pada sistem manajemen rantai suplai, pelacakan kendaraan, dan pengawasan status mesin [2].

Layanan maupun aplikasi yang mencakup organisasi yang berbeda, memiliki mekanisme dan kebijakan pengamanan aset lokal yang berbeda pula, yang berjalan berdasarkan proses bisnis lintas realm atau domain yang heterogen [3]. Pengguna, perangkat, dan layanan yang terhubung dalam suatu realm terdaftar pada otoritas autentikasi dan dikelola melalui sekumpulan proses dan kebijakan [3]. Proses autentikasi pengguna maupun entitas diimplementasikan dalam bentuk protokol autentikasi. Salah satu protokol yang digunakan untuk mengautentikasi pengguna pada suatu realm adalah Kerberos [4]. Pada protokol Kerberos, terdapat Key Distribution Center (KDC) yang berperan sebagai otoritas autentikasi. Beberapa protokol modifikasi dari Kerberos telah diajukan untuk memfasilitasi kemampuan autentikasi lintas realm, diantaranya adalah Public-Key Cryptography for Cross-Realm Authentication (PKCROSS) [5] dan Kerberos Realm Crossover (KXOVER) [6].

Tantangan yang dihadapi dalam pengembangan protokol autentikasi lintas realm adalah efisiensi dan keamanan protokol. Pada tahun 2018, Xiong dkk. melakukan analisis performa terhadap protokol PKCROSS dan PKTAPP, serta mendesain protokol autentikasi grup lintas realm berbasis kedua protokol tersebut[5]. Protokol yang didesain oleh Xiong terbukti lebih efisien daripada PKCROSS dan PKTAPP (ketika jumlah server pada PKTAPP lebih banyak 50\% dibanding jumlah remote realm). Keamanan dari protokol yang diajukan oleh Xiong dkk hanya dibahas secara informal dan belum dibuktikan secara formal. Oleh karena itu, dalam penelitian ini dilakukan verifikasi formal protokol Xiong dkk. menggunakan Scyther. Scyther merupakan tools analisis atau verifikasi protokol kriptografi berbasis metode simbolik yang dikembangkan oleh Cas Cremers [7]. Klaim keamanan yang diverifikasi adalah kerahasiaan parameter dan autentikasi entitas berdasarkan pemodelan protokol Xiong dkk.

\section{TINJAUAN PUSTAKA}

Teori dan kajian terkait topik penelitian yang dilakukan dijelaskan sebagai berikut:

\subsection{Protokol Autentikasi Cross Realm}

Protokol autentikasi adalah salah satu langkah dasar untuk mengamankan suatu komunikasi. Autentikasi bertujuan untuk menjamin bahwa pihak yang berkomunikasi adalah pihak yang benar [1]. Mekanisme 
autentikasi dapat dilakukan secara langsung oleh entitas yang saling berkomunikasi maupun melalui perantara pihak ketiga yang tepercaya, seperti KDC dalam protokol Kerberos. Pada protokol Kerberos, KDC mengontrol kunci rahasia antara klien dan server yang tergabung dalam satu domain (atau realm dalam Kerberos). Pada kasus tertentu, KDC pada suatu realm dapat mengautentikasi klien dari suatu realm kepada layanan dari server di realm yang lain (autentikasi lintas realm) [6]. Autentikasi lintas realm membutuhkan peran dari administrator di kedua realm untuk saling berkomunikasi.

\subsection{Protokol Autentikasi Cross Realm berbasis Kunci Publik [5]}

Protokol autentikasi cross realm berbasis kunci publik yang dikembangkan oleh Kaiqi Xiong menggabungkan efisiensi dari protokol PKTAPP dan PKCROSS berdasarkan aspek performa [5]. Protokol Xiong terdiri atas dua skenario berdasarkan banyaknya KDCR pada remote realm yang diakses oleh klien. Skenario yang pertama adalah Single Remote Realm (SRR), yaitu klien terhubung dengan satu remote realm). Skenario kedua adalah Multiple Remote Realm (MRR), yaitu klien terhubung dengan lebih dari satu remote realm. Pada penelitian ini, analisis formal berfokus pada skenario Single Remote Realm (SRR).

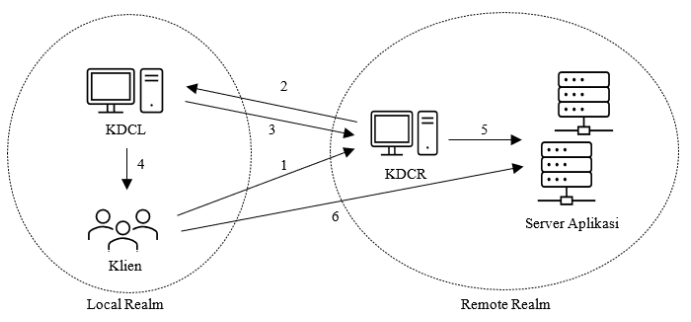

Gambar 1. Alur Pesan Skenario Single Remote Realm [5]

Misalkan $C$ merepresentasikan salah satu anggota grup yang akan mengakses layanan pada server dan menginisiasi komunikasi yang aman antara anggota grup lainnya dengan server, maka klien $C$ berperan menginisiasi kunci grup. Pada skenario SRR, klien $C$ melakukan autentikasi grup dengan kumpulan server aplikasi (dinotasikan dengan $S_{j}$, dengan $j=$ $1, \ldots, n$ ) yang tergabung dalam suatu single remote realm bersama key distribution center KDCR. Fungsi KDCR yaitu memastikan $S_{j}$ adalah penerima yang sah dan memastikan bahwa $C$ adalah pengirim yang sah berdasarkan validasi $K D C L . K D C L$ merupakan key distribution center dalam satu domain yang yang sama dengan $C$ dan berperan untuk memvalidasi identitas $C$ kepada KDCR. Daftar notasi lengkap bisa dilihat di Tabel 1.

Tabel 1. Daftar Notasi [5]

\begin{tabular}{|c|l|}
\hline \multicolumn{1}{|l|}{ Simbol } & Deskripsi \\
\hline$S_{j}$ & $\begin{array}{l}\text { Kerver Aplikasi } j \text { (jen } \\
1,2, \ldots, n)\end{array}$ \\
\hline$K D C L$ & $\begin{array}{l}\text { Key Distribution Center } \\
\text { Local atau KDC Klien }\end{array}$ \\
\hline$K D C R$ & $\begin{array}{l}\text { Key Distribution Center } \\
\text { Local atau KDC Server } \\
\text { Aplikasi }\end{array}$ \\
\hline$K_{C}$ & $\begin{array}{l}\text { Kunci rahasia antara } K D C L \\
\text { dengan } C\end{array}$ \\
\hline$K_{S_{j}}$ & $\begin{array}{l}\text { Kunci rahasia antara } K D C R \\
\text { dengan } S_{j}\end{array}$ \\
\hline$P K_{X}$ & Kunci publik $X$. \\
\hline$S K_{X}$ & Kunci privat entitas $X$ \\
\hline$M$ & Pesan \\
\hline$\{M\}_{P K_{X}}$ & $\begin{array}{l}\text { Pesan } M \text { yang dienkripsi } \\
\text { dengan kunci publik entitas } \\
X\end{array}$ \\
\hline$\{M\}_{S K_{X}}$ & $\begin{array}{l}\text { Pesan } M \text { yang } \\
\text { ditandatangani dengan } \\
\text { kunci privat entitas } X\end{array}$ \\
\hline$C e r t_{X}$ & Sertifikat entitas $X$ \\
\hline$N_{C}$ & $\begin{array}{l}\text { Nonce yang dibangkitkan } \\
\text { oleh klien } C\end{array}$ \\
\hline$T M S_{C}$ & $\begin{array}{l}\text { Timestamp yang } \\
\text { dibangkitkan oleh klien } C\end{array}$ \\
\hline$T M S 1_{R}$, & $\begin{array}{l}\text { Timestamp yang } \\
\text { dibangkitkan oleh KDCR }\end{array}$ \\
\hline$T M S 2_{R}$ & \\
\hline
\end{tabular}


Alur protokol autentikasi Xiong terdiri atas 6 langkah yang dijabarkan sebagai berikut:

$$
\text { 1. } \begin{aligned}
& C \rightarrow K D C R: N_{c}, C, K D C R: S_{1}, \ldots, S_{n}, \\
&\left\{N_{c}, K_{C, S}, K D C R: S_{1}, \ldots, S_{n}, T M S_{C}\right\}_{K_{C}}
\end{aligned}
$$

Pesan 1 : Klien $C$ menginisiasi pesan untuk berkomunikasi dengan server aplikasi $S_{j}$. Klien $C$ mengirimkan pesan ke KDCR berupa gabungan pesan terenkripsi (kunci klien dengan server $K_{C, S}$, nonce $N_{c}$, timestamp $T M S_{C}$, identitas KDCR dan server tujuan $\left(S_{1}, \ldots, S_{n}\right)$ yang dienkripsi menggunakan kunci rahasia antara $C$ dan $\left.K D C R, K_{C}\right)$ dan bagian pesan yang tidak dienkripsi, yaitu $N_{c}$, identitas $C$, serta identitas KDCR dan server tujuan $\left(S_{1}, \ldots, S_{n}\right) . \quad K D C R$ akan diautentikasi terlebih dahulu oleh $K D C L$ untuk kemudian meneruskan kunci $K_{C, S}$ kepada server $S_{j} . N_{c}$ digunakan sebagai parameter autentikasi milik $C . T M S_{C}$ disertakan untuk mencegah serangan replay.

2. $K D C R \rightarrow K D C L: N_{C}, C$,

$$
\begin{aligned}
& \left\{N_{C}, K_{C, S}, K D C R: S_{1}, \ldots, S_{n}, T M S_{C}\right\}_{K_{C}}, \\
& \left\{N_{C}, N_{K D C R}, T M S 1_{R}, \text { AuthInfo }\right\}_{P K_{K D C L}}
\end{aligned}
$$

Pesan 2 : Setelah menerima pesan dari $C$, KDCR membangkitkan $N_{K D C R}$ dan membuat pesan AuthInfo yang terdiri atas KDCR, $\operatorname{Cert}_{K D C R}, \quad\left\{N_{c}, N_{K D C R}, T M S 1_{R}, K D C L\right.$, $\left.P K_{K D C R}\right\}_{S K_{K D C R}}$. KDCR kemudian mengirimkan pesan berisi $N_{c}, N_{K D C R}$, $T M S 1_{R}$, dan AuthInfo yang dienkripsi menggunakan kunci publik $P K_{K D C L}$ yang dimiliki oleh KDCL. KDCR juga meneruskan pesan terenkripsi yang sebelumnya sudah dikirimkan oleh $C$, bersama dengan $N_{c}$ dan identitas $C$. Kedua pesan terenkripsi tersebut akan digunakan $K D C L$ untuk mengautentikasi $C$ dan $K D C R$. Cert $_{K D C R}$ pada AuthInfo memuat identitas $K D C R$ dan kunci publik $P K_{K D C R}$ yang bersifat unik. $T M S_{R}$ juga digunakan untuk mencegah serangan replay.

3. $K D C L \rightarrow K D C R:\left\{C, K D C R, N_{K D C R}\right.$,

$$
\left.K_{C, S}, \operatorname{Cert}_{K D C R}, T M S_{C}, T M S 1_{R}\right\}_{P K_{K D C R}}
$$

Pesan $3: K D C L$ mendekripsi pesan dari $K D C R$ menggunakan kunci privat dan mendekripsi pesan dari $C$ yang diteruskan oleh $K D C R$ dengan kunci $K_{C}$, lalu memverifikasi tanda tangan digital KDCR. Kemudian $K D C R$ akan memeriksa apakah $N_{c}$ yang dienkripsi dengan $K_{C}$ sama dengan nilai $N_{C}$ yang dienkripsi dengan $P K_{K D C L}$. Jika kedua nonce tersebut sama, maka $C$ adalah klien yang valid dan pesan yang diteruskan oleh $K D C R$ tidak mengalami modifikasi. KDCL juga memeriksa timestamp untuk menjamin bahwa kunci yang dikirimkan merupakan yang terbaru. $K D C L$ mengirimkan pesan kepada $K D C R$ berisi identitas $C$ dan $K D C R$, nonce $N_{K D C R}$, kunci sesi $K_{C, S}$, sertifikat $\operatorname{Cert}_{K D C L}$, serta timestamp $T M S_{C}$ dan $T M S 1_{R}$ yang dienkripsi dengan kunci publik $P K_{K D C R}$. $N_{K D C R}$ akan diperiksa oleh $K D C R$ apakah sama dengan $N_{K D C R}$ yang sudah dikirimkan pada pesan 2 .

4. $K D C L \rightarrow C:\left\{K_{C, S}, K D C L\right.$,

$$
\left.K D C R, N_{C}, T M S_{C}, T M S_{L}\right\}_{K_{C}}
$$

Pesan $4: K D C L$ mengirimkan pesan yang berisi kunci sesi $K_{C, S}$, identitas $K D C L$ dan $K D C R$, nonce $N_{c}$, serta timestamp $T M S_{C}$ dan $T M S_{L}$ yang dienkripsi dengan kunci antara $C$ dan $K D C L$. Klien $C$ mendekripsi pesan tersebut dan memeriksa apakah nonce $N_{c}$, $T M S_{C}$ dan $K_{C, S}$ sesuai dengan yang dikirimkan $C$ kepada $K D C R$. Klien $C$ juga memeriksa kesesuaian $T M S_{L}$ dengan selisih waktu transmisi.

$$
\text { 5. } \begin{aligned}
K D C R \rightarrow & S_{j}:\left\{C, K_{C, S}\right\}_{K_{S_{j}}{ }^{\prime}} \\
& \left\{N_{C}, T M S_{C}, T M S 2_{R}\right\}_{K_{C, S}}
\end{aligned}
$$

Pesan $5: K D C R$ mengirimkan pesan kepada server aplikasi $S_{j}$ berupa kunci sesi $K_{C, S}$ dan identitas klien $C$ yang dienkripsi dengan kunci antara $S_{j}$ dan $K D C R$ serta $N_{c}, T M S_{C}$, dan $T M S 2_{R}$ (timestamp baru yang dibangkitkan $K D C R$ ), dienkripsi menggunakan kunci sesi $K_{C, S} . \quad S_{j}$ 
mendekripsi pesan bagian pertama terlebih dahulu untuk memperoleh kunci sesi $K_{C, S}$ yang akan digunakan kembali untuk mendekripsi bagian pesan lainnnya untuk mendapatkan $T M S_{C}$, dan $T M S 2_{R} . T M S_{C}$ akan disimpan dan diperiksa oleh $S_{j}$ setiap menerima pesan dari KDCR untuk memastikan bahwa setiap permintaan yang diinisiasi oleh klien $C$ merupakan sesi yang baru (bukan replay) berdasarkan rentang waktu yang disepakati.

6. $S_{j} \rightarrow C:\left\{N_{C}, T M S_{C}\right\}_{K_{C, S}}$

Pesan 6 : Server aplikasi mengirimkan pesan kepada klien $C$ berupa $N_{C}$ dan $T M S_{C}$ yang dienkripsi dengan kunci sesi $K_{C, S}$. Klien $C$ mendekripsi pesan tersebut dan memeriksa apakah nonce $N_{C}$ sama dengan yang dikirim pada saat inisiasi dan timestamp $T M S_{C}$ memenuhi rentang waktu yang disepakati. Jika sama, maka klien $C$ dapat memastikan bahwa server aplikasi $S_{j}$ adalah pihak yang sah dan tidak terjadi modifikasi kunci karena hanya $S_{j}$ yang tepat menerima kunci sesi $K_{C, S}$ tersebut.

\subsection{Verifikasi Formal Protokol Kriptografi}

Keamanan merupakan salah satu hal penting yang harus dipenuhi oleh suatu protokol kriptografi. Kriteria keamanan dari protokol kriptografi dapat diverifikasi menggunakan metode informal maupun secara matematis. Penggunaan metode matematika formal untuk melakukan verifikasi keamanan biasa disebut dengan verifikasi formal [8]. Berbagai teknik yang digunakan dalam verifikasi formal diantaranya modal logic, model checking dan verifikasi model simbolik. Pada penerapannya, verifikasi formal dapat dilakukan dengan menggunakan alat otomatis seperti AVISPA [9], TAMARIN [10], dan Scyther[7].

Pada tahun 2008, Cas Creamer mempublikasikan penelitian tentang suatu metode verifikasi formal suatu protokol kriptografi berbasis model simbolik yang disempurnakan dengan aplikasi Scyther Tools. Sycther Tools menggunakan tiga cara yaitu melakukan verifikasi apakah klaim keamanan pada deskripsi protokol terpenuhi atau tidak, menghasilkan klaim keamanan yang sesuai untuk suatu protokol secara otomatis dan memverifikasinya, serta menganalisis dengan melakukan complete characterization [7].

\subsection{Penelitian Terdahulu}

Pada tahun 2010, Xu dkk. mendesain suatu protokol autentikasi cross realm dinamis berbasis Service-Oriented Architecture (SOA) dan dianalisis secara formal menggunakan metode BAN Logic [3]. Berdasarkan hasil analisis BAN Logic, protokol autentikasi yang didesain oleh $\mathrm{Xu}$ dkk. memenuhi kriteria kerahasiaan kunci sesi dan autentikasi antara entitas yang terlibat. Chen dkk., mengajukan protokol autentikasi klien antar domain 4PAKE serta memverifikasi protokol tersebut dengan pendekatan game theory dan didapatkan hasil bahwa kunci sesi pada protokol 4PAKE memenuhi sifat indistinguishable dan privacy terhadap server [11]. Pada tahun 2020, Lv dkk. merancang protokol autentikasi identitas antar domain berbasis tanda tangan digital, kemudian dianalisis menggunakan AVISPA [12]. Dari hasil analisis disimpulkan bahwa protokol yang dikembangkan oleh Lv dkk. tahan terhadap anonymous tracking, serangan man-in-themiddle (MITM), serangan replay, dan serangan penggantian identitas. Penggunaan Scyther untuk analisis protokol lintas realm pernah diterapkan pada protokol FLAT, yaitu protokol autentikasi antar domain untuk perangkat Internet-of-Things [13]. Protokol FLAT dinyatakan memenuhi sifat kerahasiaan dan autentikasi dari hasil analisis menggunakan Scyther. 


\section{METODOLOGI PENELITIAN}

Metode yang digunakan dalam penelitian ini adalah metode analisis keamanan protokol yang meliputi pemodelan protokol dan penyerang, penentuan kriteria keamanan, dan pembuktian atau pemeriksaan kriteria keamanan [14].

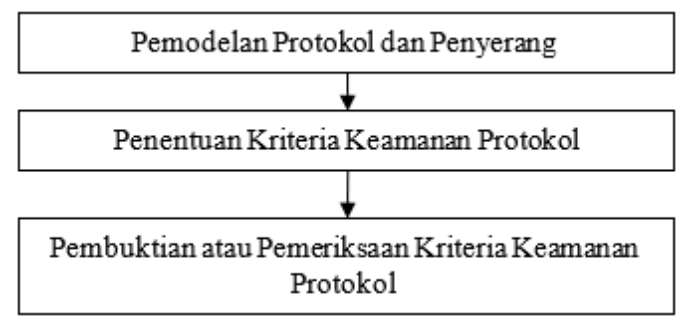

Gambar 2. Metode Analisis Keamanan Protokol

\subsection{Pemodelan Protokol dan Penyerang}

Protokol Xiang dimodelkan berdasarkan langkah-langkah protokol yang sudah dijelaskan pada Subbab 2.2. Pemodelan entitas protokol pada Scyther dilakukan pada setiap role/peran dari masing-masing entitas, yaitu peran klien $C$, $K D C R, K D C L$, dan server aplikasi $S$. Mekanisme kriptografi seperti enkripsi simetrik, enkripsi asimetrik dan pembangkitan nilai fresh sudah tersedia pada Scyther dan dapat digunakan dengan sintaks tertentu. Sementara proses pengiriman dan penerimaan pesan dimodelkan dengan sintaks send dan recv pada setiap role yang berkorespondensi. Pada pemodelan protokol Xiang, digunakan beberapa asumsi berikut :

- klien $C$ akan berkomunikasi atau memulai sesi dengan salah satu server aplikasi $S$ pada realm yang berbeda;

- elemen pesan Cert dimodelkan sebagai suatu fungsi yang memproses identitas pemilik sertifikat beserta kunci publiknya.

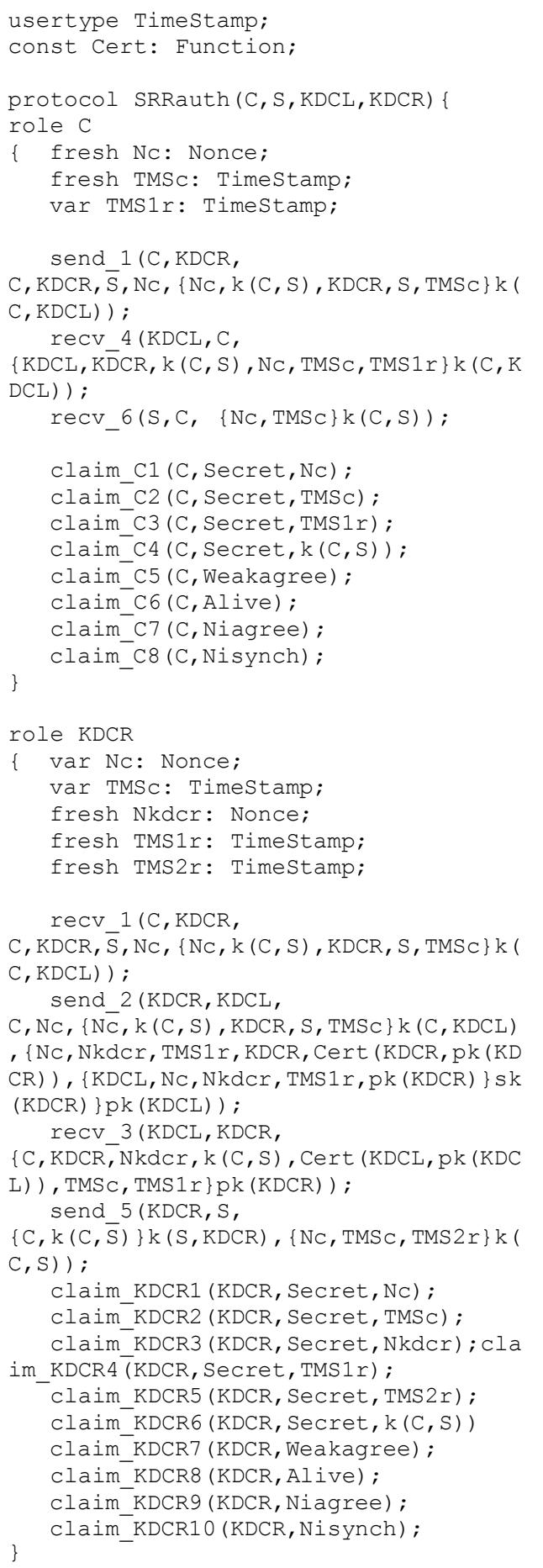




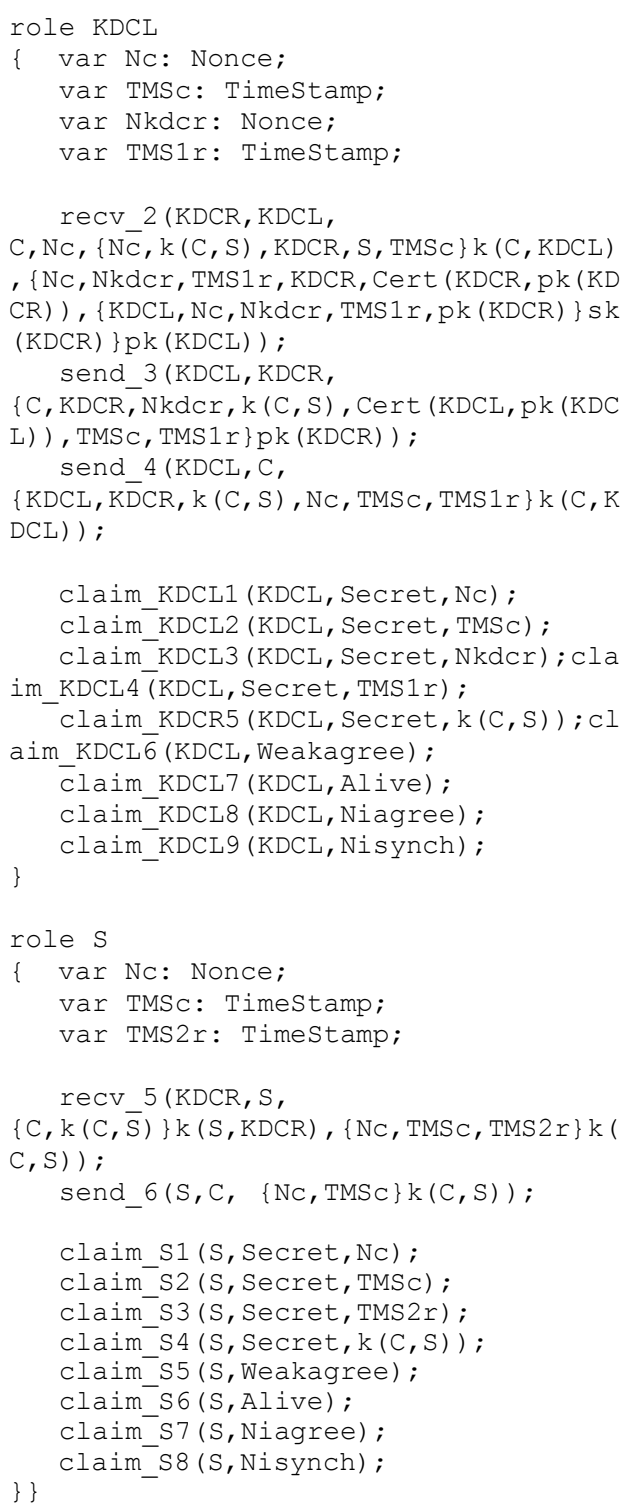

Model penyerang yang digunakan untuk menganalisis protokol ini adalah model Dolev-Yao yang sudah terintegrasi dengan Scyther Tools. Penyerang pada model Dolev-Yao memiliki kemampuan untuk menyadap dan mengintersepsi pesan, menyimpan dan mengirim pesan yang disadap maupun dibuat sendiri oleh penyerang dan terlibat sebagai entitas yang valid dalam suatu protokol [15].

\subsection{Penentuan Kriteria Keamanan Protokol}

Kriteria keamanan yang diverifikasi adalah kerahasiaan dan autentikasi. Kriteria kerahasiaan dimodelkan menggunakan klaim secrecy untuk membuktikan kerahasisan dari parameter yang dibangkitkan maupun diterima oleh entitas seperti nonce, timestamp, dan kunci sesi. Sementara kriteria autentikasi diverifikasi berdasarkan klaim berikut [16] :

- aliveness : Kapanpun $A$ menyelesaikan suatu sesi atau run protokol dengan $B$, maka $B$ telah menjalankan protokol sebelumnya;

- weak agreement : Kapanpun $A$ menyelesaikan suatu sesi atau run protokol dengan $B$, maka $B$ telah menjalankan protokol sebelumnya dengan $A$;

- non-injective agreement : Kapanpun $A$ menyelesaikan suatu sesi atau run protokol dengan $B$ dan data $x$, maka $B$ telah menjalankan protokol sebelumnya dengan $A$ dan data $x$;

- non-injective synchronization : Kapanpun $A$ menyelesaikan suatu sesi atau run protokol dengan $B$ dan data $x$, maka $B$ telah menjalankan protokol sebelumnya dengan $A$ dan data $x$ dengan urutan yang seharusnya, misalkan penerimaan pesan dengan urutan yang sama dengan pengiriman pesan.

\subsection{Pembuktian atau Pemeriksaan Kriteria Keamanan Protokol}

Setelah melakukan pemodelan protokol dan penyerang, serta menentukan kriteria keamanan protokol, langkah berikutnya adalah proses pembuktian kriteria keamanan protokol menggunakan Scyther. Scyther akan memeriksa terlebih dahulu apakah protokol yang dimodelkan tidak memiliki kesalahan sintaks. Kemudian Scyther memverifikasi kriteria keamanan 
berdasarkan klaim yang sudah dimasukkan ke dalam pemodelan. Jika terdapat serangan, maka Scyther akan menyediakan graphical user interface (GUI) yang menunjukkan grafik serangan.

\section{HASIL DAN PEMBAHASAN}

Verifikasi terhadap protokol autentikasi lintas realm Xiong dilakukan secara otomatis berdasarkan model protokol dan kriteria keamanan yang sudah ditentukan. Verifikasi dilakukan menggunakan Scyther v1.1.3 yang dikompilasi pada sistem operasi Lubuntu 20.04 x64. Konfigurasi Scyther yang digunakan adalah default dan tidak mengalami perubahan.

\subsection{Hasil Verifikasi Klaim pada Klien $C$} Verifikasi klaim pada klien $C$ mencakup kerahasiaan $N_{C}, T M S_{C}, T M S 1_{R}$, dan $K_{C, S}$ serta autentikasi (aliveness, noninjective synchronization, weak agreement, dan non-injective agreement). Gambar 3 menunjukkan hasil verifikasi klaim klien $C$. Dari 8 klaim, keseluruhan klaim dinyatakan fail dan terdapat satu serangan untuk setiap klaim.

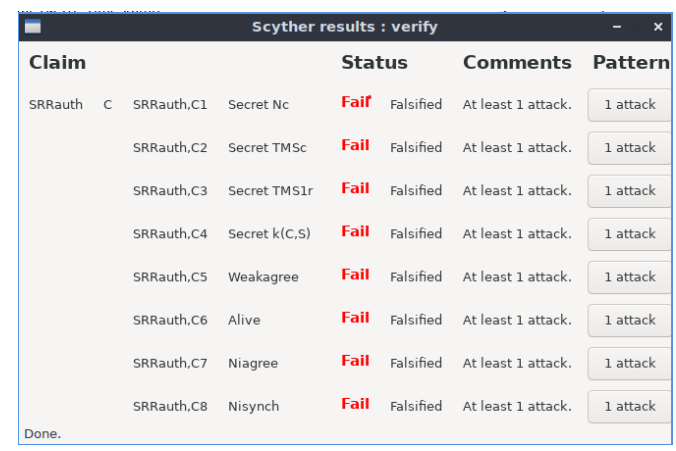

Gambar 3. Hasil Verifikasi Klaim Klien $C$ Sumber : Data Hasil Penelitian

Tahun 2021

Berikut adalah penjelasan dari setiap klaim yang dinyatakan fail atau gagal dipenuhi:
- C1 Secret $N_{C}$ : Penyerang dapat langsung mengetahui nilai nonce $N_{C}$ dengan menyadap pesan dari $C$ kepada $K D C R$ karena terdapat $N_{C}$ yang dikirim tanpa dienkripsi;

- C2 Secret $T M S_{C}, \mathrm{C} 3$ Secret $T M S 1_{R}, \mathrm{C} 4$ Secret $K_{C, S}$ : Scyther menemukan serangan pada klaim Secret $T M S_{C}$, $T M S 1_{R}$, dan $K_{C, S}$ pada entitas $C$. Scyther menghasilkan grafik serangan yang sama dari verifikasi ketiga klaim ini. Pada Run\#2 (sesi lain), penyerang Eve melakukan impersonasi (berpura-pura) sebagai $K D C L$ dan menyadap pesan dari Bob (sebagai $C$ ) untuk Agent1 (sebagai $K D C R$ ). Pesan tersebut dienkripsi menggunakan kunci Bob dengan Eve, sehingga penyerang bisa mendekripsi pesan tersebut dan mendapatkan kunci $K_{C, S}$ antara Bob (sebagai $C$ ) dan Charlie (sebagai $S$ ). Sementara di Run\#1, penyerang menyadap pesan dari Bob (sebagai $C$ ) dan Alice (sebagai $K D C R$ ), lalu mendekripsi pesan tersebut menggunakan $K_{C, S}$ yang sudah didapatkan dari Run\#2 dan memperoleh nilai timestamp $C, T M S c$ dan kunci sesi $K_{C, S}$ antara Bob dan Dave (sebagai $S$ ) pada Run\#2. Penyerang juga memperoleh $T M S 1_{R}$, hanya saja tidak bisa dipastikan jika timestamp tersebut adalah yang asli, sehingga keterangan yang muncul adalah TimeStampIntruder1 (bisa dibangkitkan oleh penyerang sendiri ketika membentuk pesan ke-6 untuk $S$ );

- C5 Weakagree : Klaim weakagree tidak terpenuhi pada klien $C$ karena ketika $C$ mengirim pesan 1 yang ditujukan untuk $K D C R$, tidak ada jaminan bahwa klien $C$ benar-benar berkomunikasi dengan $K D C R$ yang valid. Berdasarkan grafik serangan yang dihasilkan, penyerang berpura-pura sebagai KDCR yang menerima pesan dari $C$ (Run\#1) dan 
meneruskan ke $K D C L$. Pada Run\#2 atau di sesi yang lain $K D C R$ juga mengelabui $K D C L$ ketika mengirim pesan 2;

- C6 Alive, C7 Niagree, C8 Nisynch : Verifikasi Scyther dari ketiga klaim ini menghasilkan grafik yang sama. Klaim aliveness tidak terpenuhi karena $C$ tidak berkomunikasi dengan entitas yang sah ketika mengirim pesan 1 , serta menerima pesan 4 dan 6. Sementara klaim Nisynch dan Niagree tidak terpenuhi karena penyerang yang berpura-pura sebagai $K D C L$ dapat membuat pesan 4 yang palsu menggunakan timestamp $T M S 1_{R}$ yang dibangkitkan sendiri. Sehingga $C$ menerima timestamp palsu pada pesan 4 dan tidak sesuai dengan isi pesan yang seharusnya.

\subsection{Hasil Verifikasi Klaim pada $K D C R$}

Pada $K D C R$, klaim yang diverifikasi antara lain kerahasiaan $N_{C}, T M S_{C}, N_{K D C R}$ $T M S 1_{R}, T M S 1_{R}$, dan $K_{C, S}$ serta klaim autentikasi (aliveness, non-injective synchronization, weak agreement, dan non-injective agreement). Hasil verifikasi klaim pada $K D C R$ ditunjukkan pada Gambar 5. Dari 9 klaim, 8 klaim dinyatakan fail dan satu klaim, yaitu kerahasiaan $N_{K D C R}$ berhasil dipenuhi.

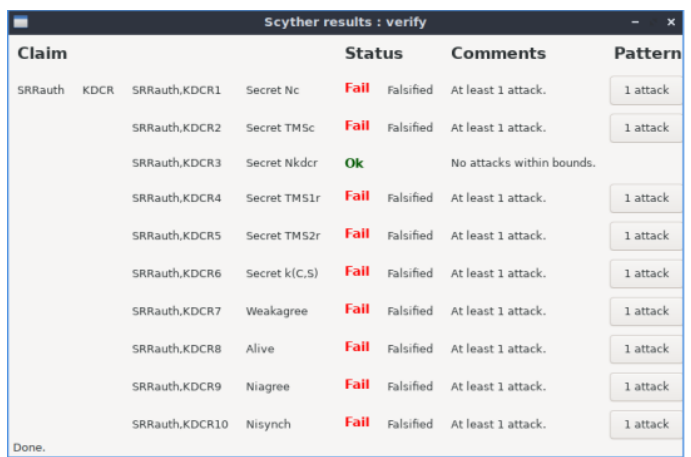

Gambar 4. Hasil Verifikasi Klaim KDCR Sumber : Data Hasil Penelitian

Tahun 2021

Klaim KCDR3, Secret $N_{K D C R}$ dipenuhi karena nonce $K D C R$ dienkripsi dengan kunci publik $K D C R$. Penyerang harus mengetahui kunci privat $K D C R$ untuk mendekripsi pesan 3 dan mendapatkan $N_{K D C R}$.

Berikut adalah penjelasan dari setiap klaim yang dinyatakan fail atau gagal dipenuhi:

- KDCR1 Secret $N_{C}$ : Sama seperti hasil verifikasi pada klaim $\mathrm{C} 1$ Secret $N_{C}$, penyerang mengetahui nilai nonce $N_{C}$ dari bagian pesan 1 yang tidak dienkripsi dengan berpura-pura sebagai $K D C R$ menyadap pesan dari $C$ kepada $K D C R$ yang asli;

- KDCR2 Secret $T M S_{C}$ : Scyther menemukan serangan pada klaim Secret $T M S_{C}$ pada entitas KDCR. Timestamp $T M S_{C}$ tidak bisa dipastikan sebagai timestamp yang asli dan dapat dibangkitkan oleh penyerang (TimeStampIntruder1) dan disisipkan pada pesan 1;

- KDCR4 Secret $T M S 1_{R}$ : Berdasarkan hasil verifikasi Scyther, penyerang melakukan impersonasi KDCL pada Run\#4 dan menyadap pesan 1 untuk memperoleh kunci sesi $K_{C, S}$ antara Bob (sebagai $C$ ) dan Charlie (sebagai $S$ ). Pada sesi lain, yaitu Run\#2, penyerang menyadap pesan 4 dari Charlie (sebagai $K D C L$ ) kepada Bob (sebagai $C$ ), kemudian mendekripsi pesan tersebut menggunakan $K_{C, S}$ yang sudah didapatkan dari Run\#4 dan memperoleh nilai timestamp TMS1r;

- KDCR5 Secret $T M S 2_{R}$ : Grafik serangan dari klaim ini hampir serupa dengan klaim KDCR4 Secret $T M S 1_{R}$. Namun pesan yang disadap untuk mendapatkan $T M S 2_{R}$ berbeda, yaitu pesan 5. Penyerang menggunakan $K_{C, S}$ antara Bob (sebagai $C$ ) dan Dave (sebagai $S$ ) di Run\#4 dan mendekripsi pesan 5 pada Run\#1 untuk mendapat $T M S 2_{R}$.

- KDCR6 Secret $K_{C, S}$ : Seperti pada klaim KDCR4 Secret $T M S 1_{R}$ dan KDCR5 Secret $T M S 2_{R}$, penyerang impersonasi 
sebagai KDCL dan menyadap serta mendekripsi pesan 1 untuk memperoleh $K_{C, S}$;

- KDCR7 Weakagree, KDCR8 Alive : KDCL memiliki kemungkinan berkomunikasi dengan penyerang yang mengimpersonasi KDCR ketika menerima pesan 1 , meskipun komunikasi pesan berikutnya yaitu pesan 3 sudah dengan $K D C R$ yang valid. Sehingga weakagree pada $K D C R$ tidak terpenuhi. Sementara klaim aliveness tidak terpenuhi karena KDCL yang mengirimkan pesan 3 sebelumnya sudah berkomunikasi dengan $K D C R$ di sesi yang lain;

- KDCR9 Niagree, KDCR10 Nisynch: Klaim nisynch dan niagree gagal dipenuhi karena penyerang dapat mengimpersonasi klien $C$ serta membangkitkan $N_{C}$ dan $T M S_{C}$ palsu. Penyerang juga mendapat $K_{C, S}$ dengan berpura-pura sebagai $K D C L$ yang menerima pesan 1 . Penyerang kemudian membentuk pesan 1 yang baru menggunakan nonce dan timestamp palsu yang dienkripsi dengan kunci $K_{C, S}$. Dengan demikian, KDCR tidak menerima pesan yang seharusnya berisi nonce dan timestamp valid dari $C$.

\subsection{Hasil Verifikasi Klaim pada $K D C L$}

Klaim yang diverifikasi pada $K D C L$ diantaranya kerahasiaan $N_{C}, T M S_{C}, N_{K D C R}$ $T M S 1_{R}, \quad K_{C, S}$ dan klaim autentikasi (aliveness, non-injective synchronization, weak agreement, dan non-injective agreement). Gambar 4 menunjukkan hasil verifikasi klaim pada $K D C L$. Dari 9 klaim, 8 klaim dinyatakan fail dan terdapat satu klaim yang berhasil dipenuhi, yaitu kerahasiaan $N_{K D C R}$.

Sama seperti klaim pada KDCR, klaim KCDL3, Secret $N_{K D C R}$ dipenuhi karena nonce $K D C R$ dienkripsi dengan kunci publik $K D C R$ pada pesan 3 dan penyerang harus mengetahui kunci privat $K D C R$ untuk mendekripsi pesan tersebut.

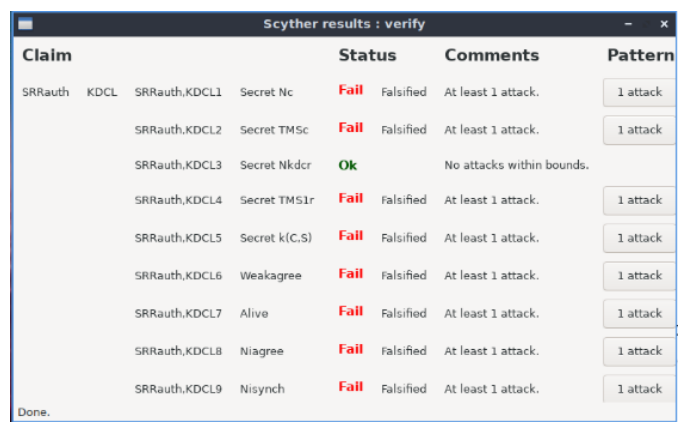

Gambar 5. Hasil Verifikasi Klaim KDCL

Sumber : Data Hasil Penelitian

Tahun 2021

Berikut adalah penjelasan dari setiap klaim yang dinyatakan fail atau gagal dipenuhi:

- KDCL1 Secret $N_{C}$ : Hasil verifikasi klaim ini sama seperti hasil verifikasi klaim C1 Secret $N_{C}$ dan KDCR1 Secret $N_{C}$, penyerang mendapatkan nilai $N_{C}$ dari bagian pesan 1 yang tidak dienkripsi dengan melakukan impersonasi $K D C L$ menyadap pesan dari $C$ kepada $K D C R$ yang asli;

- KDCL2 Secret $T M S_{C}$ : Timestamp $T M S_{C}$ yang diterima $K D C L$ pada pesan 2 tidak bisa dipastikan sebagai timestamp yang asli dan dapat dibangkitkan oleh penyerang (TimeStampIntruder1) dan disisipkan pada pesan 1 untuk kemudian diteruskan kepada $K D C L$ di pesan 2;

- KDCL4 Secret $T M S 1_{R}$ : Berdasarkan hasil verifikasi Scyther, mekanisme serangan yang dihasilkan serupa dengan hasil verifikasi klaim Secret $T M S 1_{R}$ pada KDCR4. Penyerang mengimpersonasi KDCL pada Run\#4 dan menyadap pesan 1 untuk memperoleh kunci sesi $K_{C, S}$ antara Bob (sebagai $C$ ) dan Charlie (sebagai $S$ ). Pada sesi lain (Run\#1), penyerang menyadap pesan 4 dari Charlie (sebagai KDCL) kepada Bob 
(sebagai $C$ ) dan mendekripsi pesan tersebut menggunakan $K_{C, S}$ yang sudah didapatkan dari Run\#4 untuk memperoleh nilai $T M S 1 r$;

- KDCL5 Secret $K_{C, S}$ : Penyerang mengimpersonasi $K D C L$ lalu menyadap pesan 1 pada Run\#4 dan mendekripsi pesan tersebut untuk mendapatkan kunci sesi $K_{C, S}$;

- KDCL6 Weakagree, KDCL7 Alive : $K D C L$ kemungkinan berkomunikasi dengan penyerang sebagai $K D C R$ palsu ketika menerima pesan 2, meskipun pada komunikasi pesan berikutnya (pesan 3) sudah dengan KDCR asli. Sehingga weakagree pada $K D C R$ tidak terpenuhi. Sementara klaim aliveness tidak terpenuhi karena KDCL yang mengirimkan pesan 3 sudah berkomunikasi sebelumnya dengan $K D C R$ di sesi yang lain;

- KDCL8 Niagree, KDCR9 Nisynch : Grafik yang dihasilkan dari verifikasi klaim nisynch dan niagree menunjukkan pola serangan sama. Pada Run\#2, penyerang mengimpersonasi $K D C R$ dan menyadap pesan 1 untuk mendapatkan bagian pesan $\left\{N_{c}, K_{C, S}, K D C R: S_{1}, \ldots, S_{n}\right.$ , $\left.T M S_{C}\right\}_{K_{C}}$. Kemudian penyerang juga mengimpersonasi $C$ pada Run\#3 dan mengirim pesan 1 palsu yang menggunakan $T M S_{C}$ yang dibangkitkan sendiri oleh penyerang. KDCR di Run\#3 mengira bahwa dia berkomunikasi dengan $C$ yang asli sehingga melanjutkan proses dengan membentuk pesan 2 untuk dikirimkan kepada KDCL. Penyerang kembali menyadap pesan dan memperoleh bagian pesan 2, yaitu $\left\{N_{c}, N_{K D C R}, T M S 1_{R}, \text { AuthInfo }\right\}_{P K_{K D C L}}$.

Setelah memperoleh informasi yang cukup dari dua sesi lain, yaitu Run\#2 dan Run\#3, penyerang mengimpersonasi $K D C R$ pada sesi yang asli (Run\#1) dan membentuk pesan 2 palsu untuk dikirimkan kepada KDCL. KDCL menerima pesan 2 yang berbeda dengan pesan 2 yang seharusnya dari Run\#1 atau sesi yang asli. Nonce $N_{C}$ didapatkan dari Run\#2. $N_{K D C R}$ dan $T M S 1_{R}$ dari Run\#3. Oleh karena itu, klaim nisynch dan niagree tidak terpenuhi.

\subsection{Hasil Verifikasi Klaim pada $S$}

Klaim yang diverifikasi pada server $S$ antara lain kerahasiaan $N_{C}, T M S_{C}, T M S 2_{R}$, dan $K_{C, S}$ serta klaim autentikasi (aliveness, non-injective synchronization, weak agreement, dan non-injective agreement). Gambar 5 menunjukkan hasil verifikasi klaim pada server $S$. Dari 8 klaim, seluruh klaim dinyatakan fail dan terdapat serangan untuk setiap klaim.

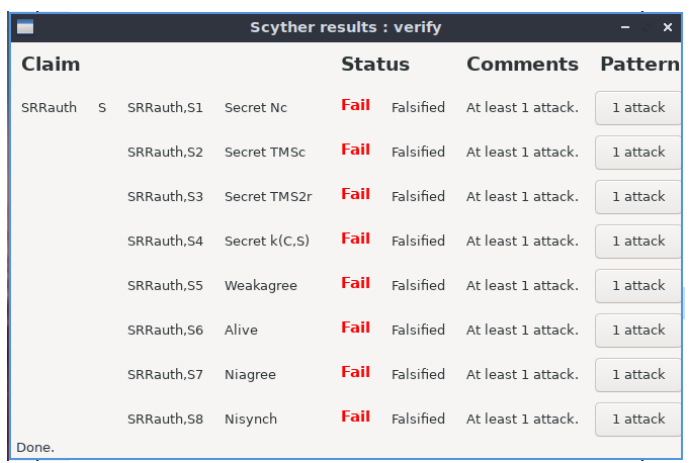

Gambar 6. Hasil Verifikasi Klaim $S$

Sumber : Data Hasil Penelitian

Tahun 2021

Berikut adalah penjelasan dari setiap klaim yang dinyatakan fail atau gagal dipenuhi:

- S1 Secret $N_{C}$ : Penyerang dapat mengetahui nilai nonce $N_{C}$ dengan menyadap pesan dari $C$ kepada $K D C R$ karena terdapat $N_{C}$ yang dikirim tanpa dienkripsi;

- S2 Secret $T M S_{C}, \mathrm{~S} 3$ Secret $T M S 2_{R}, \mathrm{~S} 4$ Secret $K_{C, S}$ : Hasil verifikasi ketiga klaim ini menunjukkan grafik yang sama. Penyerang mengimpersonasi $K D C L$ pada Run\#2, menyadap pesan 1 dan mendapatkan $K_{C, S}$. Sementara $T M S_{C}$ dan 
$T M S 2_{R}$ dibangkitkan sendiri oleh penyerang untuk membuat pesan 5 pada Run\#1 dengan kunci sesi $K_{C, S}$ dari Run\#2;

- S5 Weakagree, S6 Alive : Grafik hasil verifikasi menunjukkan klaim Weakagree tidak dipenuhi dari sisi $K D C R$ dan Aliveness tidak dipenuhi dari sisi $K D C L$ sehingga berdampak terhadap pesan 5 yang diterima oleh $S$. Hal ini dikarenakan peran $S$ bukan sebagai inisiator untuk $K D C R$ maupun $K D C L$;

- S7 Niagree, S8 Nisynch : Grafik hasil verifikasi klaim nisynch dan niagree menunjukkan pola serangan yang serupa. Pada Run\#2, penyerang mengimpersonasi $K D C L$ dan menyadap pesan 1, kemudian mendekripsi pesan tersebut untuk mendapat $K_{C, S}$. Kemudian pada Run\#1, penyerang merekonstruksi pesan 5 menggunakan $N_{C}, T M S_{C}$, dan $T M S 2_{R}$ palsu (dibangkitkan sendiri oleh penyerang) untuk dikirimkan kepada $S$. Sehingga dapat disimpulkan jika $S$ tidak memenuhi klaim nisynch dan niagree karena tidak menerima pesan 5 yang seharusnya (isi pesan berbeda) dan bukan dari entitas $K D C R$ yang asli.

\section{KESIMPULAN}

Kesimpulan yang didapatkan dari hasil penelitian ini antara lain:

- Dari 35 klaim yang diverifikasi terdapat 33 klaim yang fail (gagal dibuktikan) yaitu kerahasiaan parameter $N_{C}, T M S_{C}$, $T M S 1_{R}, T M S 2_{R}$, dan $K_{C, S}$, serta seluruh klaim autentikasi (alive, weakagree, niagree, nisynch) pada seluruh entitas;

- Dari 35 klaim yang diverifikasi terdapat 2 klaim yang $O K$ (berhasil dibuktikan) yaitu kerahasiaan parameter $N_{K D C R}$ pada entitas $K D C R$ dan $K D C L$.

\section{SARAN}

Saran-saran untuk untuk penelitian selanjutnya antara lain:

- Melakukan analisis formal menggunakan metode lain yang mendukung kriteria autentikasi yang lebih ketat dan mampu mendeteksi serangan replay;

- Melakukan analisis formal terhadap skenario Multiple Remote Realm (MRR).

\section{DAFTAR PUSTAKA}

[1] W. He dan L. D. Xu, "Integration of Distributed Enterprise Applications: A Survey," IEEE Trans. Ind. Inf., vol. 10, no. 1, hlm. 35-42, Feb 2014, doi: 10.1109/TII.2012.2189221.

[2] H. S. Jennath, S. Adarsh, dan V. S. Anoop, "Distributed IoT and Applications: A Survey," dalam Integrated Intelligent Computing, Communication and Security, vol. 771, A. N. Krishna, K. C. Srikantaiah, dan C. Naveena, Ed. Singapore: Springer Singapore, 2019, hlm. 333-341. doi: 10.1007/978-981-10-8797-4_35.

[3] J. Xu, D. Zhang, L. Liu, dan X. Li, "Dynamic Authentication for CrossRealm SOA-Based Business Processes," IEEE Trans. Serv. Comput., vol. 5, no. 1, hlm. 20-32, Jan 2012, doi: 10.1109/TSC.2010.33.

[4] W. S. Albaldawi dan R. M. Almuttairi, "Kerberos Authentication for Big Data Applications on Cloud Environment," $J$. Phys.: Conf. Ser., vol. 1804, no. 1, hlm. 012062, Feb 2021, doi: 10.1088/17426596/1804/1/012062.

[5] K. Xiong, "The performance analysis of public key cryptography-based authentication," ICST Transactions on Security and Safety, vol. 4, no. 14, hlm. 154770, Mei 2018, doi: 10.4108/eai.155-2018.154770.

[6] O. C. Bellatriu, "Kerberos Realm Crossover," Master Thesis, Eindhoven University of Technology, Eindhoven, 2016.

[7] Cas Cremers, "Scyther User Manual." 2014. Diakses: Feb 13, 2017. [Daring]. Tersedia pada: 
https://github.com/cascremers/scyther/b lob/master/gui/scyther-manual.pdf

[8] C. Boyd, A. Mathuria, dan D. Stebila, Protocols for Authentication and Key Establishment. Berlin, Heidelberg: Springer Berlin Heidelberg, 2020. doi: 10.1007/978-3-662-58146-9.

[9] L. Viganò, "Automated Security Protocol Analysis With the AVISPA Tool," Electronic Notes in Theoretical Computer Science, vol. 155, hlm. 6186, Mei 2006, doi: 10.1016/j.entcs.2005.11.052.

[10] The Tamarin Team, "Tamarin-Prover Manual.” 2018. Diakses: Apr 07, 2017. [Daring]. Tersedia pada: https://tamarinprover.github.io/manual/tex/tamarinmanual.pdf

[11]L. Chen, H. W. Lim, dan G. Yang, "Cross-Domain Password-Based Authenticated Key Exchange Revisited," ACM Trans. Inf. Syst. Secur., vol. 16, no. 4, hlm. 1-32, Apr 2014, doi: 10.1145/2584681.

[12]Y. Lv, W. Liu, dan Z. Wang, "Heterogeneous Cross-Domain Identity Authentication Scheme Based on Proxy Resignature in Cloud Environment," Mathematical Problems in Engineering, vol. 2020, hlm. 1-12, Nov 2020, doi: $10.1155 / 2020 / 2078032$.

[13]M. L. B. A. Santos, J. C. Carneiro, A. M. R. Franco, F. A. Teixeira, M. A. A. Henriques, dan L. B. Oliveira, "FLAT: Federated lightweight authentication for the Internet of Things," Ad Hoc Networks, vol. 107, hlm. 102253, Okt 2020, doi: 10.1016/j.adhoc.2020.102253.

[14]A. Datta, S. Jha, N. Li, D. Melski, dan T. Reps, "Analysis Techniques for Information Security," Synthesis Lectures on Information Security, Privacy, and Trust, vol. 2, no. 1, hlm. 1164, Apr 2010, doi: 10.2200/S00260ED1V01Y201003SPT 002.

[15]D. Dolev dan A. Yao, "On the Security of Public Key Protocols," IEEE Transactions on information theory, vol. 29, no. 2, hlm. 198-208, 1983.
[16]T. Lauser, D. Zelle, dan C. Krauß, "Security Analysis of Automotive Protocols," dalam Computer Science in Cars Symposium, Feldkirchen Germany, Des 2020, hlm. 1-12. doi: $10.1145 / 3385958.3430482$. 